Available online di: http://ejournal-balitbang.kkp.go.id/index.php/JSJ/index

\title{
PENGOLAHAN UDANG PUTIH (Litopenaeus vannamei) KUPAS MENTAH BEKU DI PT. PULAU MAS KHATULISTIWA, PONTIANAK-KALIMANTAN BARAT
}

\section{FROZEN RAW PEELED AND DEVEINED WHITE SHRIMPS (Litopenaeus vannamei) PROCESSING AT PT.PULAU MAS KHATULISTIWA, PONTIANAK- WEST KALIMANTAN}

\author{
Medal Lintas Perceka ${ }^{1}$, Rufnia Ayu Afifah ${ }^{2}$, Petrus Pieter Ringgo ${ }^{2}$ \\ ${ }^{1}$ Prodi Pengolahan Hasil Laut Politeknik Kelautan dan Perikanan Jembrana \\ Desa Pengambengan, Negara, Jembrana; Telepon (0365)-4503980 Bali 82218 \\ ${ }^{2}$ Prodi Teknologi Pengolahan Hasil Perikanan Politeknik Ahli Usaha Perikanan \\ JI. AUP No. 1 Pasar Minggu-Jakarta Selatan; Telepon (021)-7805030 Jakarta 12520
}

“Email: medalintasperceka@gmail.com ${ }^{1)}$, rufniafi@gmail.com²), petruspieterringgo@gmail.com ${ }^{2)}$

\section{ABSTRAK}

Udang vaname (Litopenaeus vannamel) merupakan udang yang saat ini dikembangkan di Indonesia. Produk udang beku merupakan produk yang digemari oleh masyarakat Indonesia. Tujuan dilakukannya penelitian ini yaitu untuk mengetahui mutu bahan baku udang, penerapan rantai dingin dalam proses pengolahan udang PND, mutu produk akhir, rendemen serta produktivitas tenaga kerja di PT.Pulau Mas Khatulistiwa. Bahan baku udang masih tergolong kedalam kategori udang segar dikarenakan rata-rata nilai organoleptiknya 7,6. Kandungan mikroba dalam bahan baku udang masih sesuai dengan standar SNI. Dalam bahan baku udang tidak ditemukan jenis antibiotik kloramfenikol, nitrofuran, maupun tetrasiklin. Produk akhir udang PND memiliki nilai organoleptik 8 , kandungan mikrobiologi sesuai dengan standar SNI, dan rata-rata rendemen udang $82,54 \%$. Nilai rata-rata produktifitas tenaga kerja di PT. Pulau Mas Khatulistiwa Pontianak-Kalimantan Barat yaitu 16,22 $\mathrm{kg} / \mathrm{jam} / \mathrm{orang}$.

Kata Kunci: Produk olahan, Udang PND, udang vaname

\section{ABSTRACT}

White shrimp (Litopenaeus vannamei) is a shrimp that is currently being developed in Indonesia. Frozen shrimp products are products that are favored by Indonesian people. The aims of this study were to determined quality of raw materials; cold chain application of PND processing; quality of PND shrimps; yield of product and labor productivity at PT.Pulau Mas Khatulistiwa. Raw material of shrimps were still classified as fresh shrimps (the value of organeoleptic test was 7,6). Microbial testing showed that raw shrimps microbial still fulfill SNI requirements. No antibiotik (chloramphenicol, nitrofuran, tetracyclin) were found in raw materials. Raw PND shrimps had an organoleptic value of 8 . Microbiology testing of PND shrimps stil fulfill SNI requirements. Yield of PND was $82,54 \%$ and labor productivity was $16,22 \mathrm{~kg} /$ hour/labor at PT. Pulau Mas Khatulistiwa PontianakWest Kalimantan.

Keywords: Processed Product, Raw PND, Vaname shrimps

\section{PENDAHULUAN}

Udang merupakan komoditas unggulan Indonesia. Udang menempati posisi pertama dari segi volume produksi perikanan tangkap maupun budidaya. Volume produksi perikanan tangkap dan budidaya udang mengalami peningkatan dari tahun 2012-2017. Pada tahun 2017, komoditas udang memberikan kontribusi sebesar $5,71 \%$ terhadap produksi perikanan budidaya. Hasil tangkapan udang terbesar dihasilkan dari WPP 571 yaitu Selat Malaka dan Laut Andaman yaitu sebesar 100.615 ton. Udang menempati posisi pertama baik dari segi volume maupun nilai ekspor hasil perikanan Indonesia pada tahun 2021-2017 (KKP 2018). 
Available online di: http://ejournal-balitbang.kkp.go.id/index.php/JSJ/index

Tingginya permintaan ekspor udang Indonesia merupakan kesempatan bagi Indonesia untuk dapat mengembangkan pengolahan udang menjadi komoditas ekspor Indonesia.

Udang merupakan komoditi yang mudah mengalami kerusakan sehingga memiliki umur simpan yang terbatas. Pengolahan udang menjadi produk lainnya merupakan salah satu cara untuk memperpanjang masa simpan udang. PT.Pulau Mas Khatulistiwa yang lokasinya di Pontianak, Kalimantan Barat merupakan salah satu perusahaan yang bergerak dalam proses pengolahan udang. PT.Pulau Mas Khatulistiwa mengolah udang vaname menjadi udang PND mentah beku. Pengamatan proses pengolahan udang vaname menjadi produk udang PND mentah beku perlu dilakukan untuk memonitoring mutu/kualitas produk akhir sehingga produk tersebut aman untuk dikonsumsi oleh masyarakat. Oleh karena itu penelitian ini perlu dilakukan di salah satu perusahaan yang bergerak dalam bidang pengolahan udang.

\section{BAHAN DAN METODE}

\section{Bahan dan Alat}

Bahan utama yang digunakan dalam penelitian ini adalah udang vannamei (Litopenaeus vannamei), es dan air. Alat yang digunakan yaitu scoresheet organoleptik udang segar (SNI 01-2728.1-2006) dan scoresheet udang PND (SNI 01-3457.3-2014).

\section{Tahapan Penelitian}

Bahan baku udang vaname yang berasal dari supplier di daerah Pontianak diangkut menggunakan mobil truk dan box fiber yang berisi udang dan es curai. Es dan udang disusun secara bergantian di dalam box fiber. Pada bagian atas ditambahkan air dingin sehingga seluruh bagian udang terendam es. Bahan baku udang yang sudah sampai di PT. Pulau Mas Khatulistiwa diuji secara organoleptik dan mikrobiologi. Setelah dilakukan pengamatan mutu bahan baku udang, dilakukan pengamatan penerapan rantai dingin saat kegiatan produksi udang PND, pengamatan mutu produk akhir, rendemen serta produktivitas tenaga kerja di PT.Pulau Mas Khatulistiwa.

\section{Uji Organoleptik Bahan Baku Udang (SNI 01-2728.1-2006)}

Pengujian organoleptik udang segar mengacu pada SNI 01-2728.1-2006. Parameter yang diamati meliputi kenampakan, bau dan tekstur. Pengujian organoleptik produk akhir mengacu pada SNI 3457:2014. Parameter yang diamati yaitu lapisan es pada permukaan produk, tingkat kekeringan produk (dehidrasi), serta perubahan warna pada produk udang kupas mentah beku. Pengamatan secara organoleptik juga dilakukan pada produk akhir setelah dilelehkan yang meliputi kenampakan, bau dan tekstur.

\section{Uji Organoleptik Udang PND (SNI 3457:2014)}

Pengujian organoleptik udang mentah beku PND mengacu kepada SNI 3457:2014 yang meliputi pengamatan saat kondisi beku dan setelah dithawing. Pada saat kondisi beku, parameter yang diamati meliputi lapisan es pada produk beku, kondisi dehidrasi, serta perubahan warna yang terjadi. Pada saat setelah dithawing, parameter yang diamati meliputi kenampakan, baud an tekstur.

\section{Uji ALT (SNI 01-2332.3-2006)}

Prinsip pengujian jumlah total mikroba pada bahan baku udang dan produk akhir dengan metode Total Plate Count (TPC) adalah penghitungan jumlah mikroba pada sampel dengan cara pengenceran. Sampel sebanyak 10 gram ditambahkan dengan $90 \mathrm{~mL} \mathrm{NaCl}$ $0,85 \%$. Campuran larutan diambil sebanyak $1 \mathrm{~mL}$ dan dimasukkan kedalam tabung reaksi yang berisi $9 \mathrm{~mL}$ larutan garam $0,85 \%$ (pengenceran $10^{-2}$ ). Proses pengenceran dilakukan sampai $10^{-5}$. Campuran larutan masing-masing diambil sebanyak $1 \mathrm{~mL}$ dan dipindahkan kedalam cawan petri. Media agar dimasukkan kedalam cawan petri sebanyak $10 \mathrm{~mL}$ dengan 
Available online di: http://ejournal-balitbang.kkp.go.id/index.php/JSJ/index

metode tuang. Media agar didiamkan sampai dingin dan mengeras. Cawan petri dimasukkkan kedalam incubator, suhu $30^{\circ} \mathrm{C}$ selama 48 jam dengan posisi cawan dibalik. Jumlah koloni mikroba yang dapat dihitung yaitu yang punya jumlah koloni 20-200 koloni.

\section{Uji Salmonella (SNI 01-2332.2-2006)}

Pengujian Salmonella pada bahan baku udang dan produk akhir mengacu pada SNI 01-2332.2-2006. Pengujian Salmonella dilakukan dengan cara sampel udang sebanyak $25 \mathrm{~g}$ ditambahkan dengan $225 \mathrm{~mL}$ Lactose Broth, dihomogenkan dan dinkubasi selama 24 jam. Pengkayaan dilakukan menggunakan Rappaport-Vassiliadis (RV) dan Tetrathionat Broth (TTB). Isolasi Salmonella dilakukan dengan media BSA, XLD, dan HE. Pengamatan morfologi Salmonella dilakukan dengan menggunakan media TSI dan LIA. Hasil positif dari pengujian TSI dan LIA diuji kembali dengan uji urease, indol, MR, VP, simmon sitrat, KCN, laktosa, dulcitol, sukrosa dan malonate.

\section{Uji E.coli (01-2332.1-2006)}

Pengujian E.coli dilakukan dengan cara sampel udang sebanyak 25 gram dihomogenkan dengan $225 \mathrm{~mL}$ BFP, kemudian dilakukan pengenceran dengan media LTB. Hasil positif menunjukkan keruhnya media LTB. Hasil positif E.coli pada media LTB diinokulasi menggunakan EC Broth, diinkubasi selama 48 jam pada suhu $45^{\circ} \mathrm{C}$. Hasil positif pada media EC broth diinokulasi kembali pada media LEMB, diinkubasi selmaa 24 jam pada suhu $35^{\circ} \mathrm{C}$. Koloni positif pada media LEMB diinokulasikan ke dalam media PCA. Pembuktian keberadaan E.coli dalam sampel diuji lanjut dengan uji indol, MR, VP, sitrat dan pewarnaan gram.

\section{Uji Vibrio cholera (SNI 01-2332.4-2006)}

Pengujian Vibrio Cholera dilakukan dengan cara sampel udang sebanyak 25 gram ditambahkan dengan $225 \mathrm{~mL}$ larutan Alkaline Pepton Water (APW) kemudian dihomogenisasi selama 2-3 menit. Pengenceran dilakukan dengan cara melarutkan $1 \mathrm{~mL}$ homogenate ke dalam $9 \mathrm{~mL}$ APW. Homogenat diinkubasi pada suhu $36^{\circ} \mathrm{C}$ selama 24 jam. APW digoreskan pada agar TCBS. Pendugaan Vibrio cholera diamati pada TCBS agar. Pemurnian dilakukan dengan cara mengambil 3 koloni terduga V.cholera dari agar TCBS kemudian koloni digoreskan pada T1N1 agar atau TSA 1,5\% NaCl dan diinkubasi pada suhu 36 oC selama 24 jam. Pembuktian keberadaan Vibrio cholera pada sampel diuji lanjut dengan uji oksidase, uji sensitivitas, TSIA dan KIA, uji ONPG, uji oksidatif-fermentatif, dan pewarnaan gram, uji hidrolisis urea, uji arginin dihidrolase, uji toleransi terhadap garam, uji voges-prokaeur, uji fermentasi karbohidrat, uji serologi.

\section{HASIL DAN PEMBAHASAN}

\section{Mutu bahan baku}

Bahan baku udang yang berasal supplier di daerah Pontianak diangkut menggunakan truk dan box fiber ke PT.Pulau Mas Khatulistiwa. Udang dan es disusun secara bergantian, pada bagian akhir ditambahkan air dingin untuk menjaga mutu udang agar masih segar ketika sampai di PT.Pulau Mas Khatulistiwa. Zhu et al. 2015 menyatakan bahwa penerapan rantai dingin diperlukan untuk menjaga produk beku atau dingin dalam lingkungan dengan suhu tertentu baik selama produksi, penyimpanan, transportasi, maupun penjualan agar kualitas produk dapat terjaga dengan baik.

Bahan baku udang yang sudah sampai di PT.Pulau Mas Khatulistiwa dilakukan pengecekan terlebih dahulu secara organoleptik oleh Quality Control (QC). Hasil pengujian organoleptik bahan baku udang vaname dapat dilihat pada Tabel 1. Berdasarkan Tabel 1 dapat dilihat bahwa bahan baku udang vaname yang berasal dari supplier dari daerah Pontianak memiliki nilai organoleptik dengan rentang 7-8. Hal ini menunjukkan bahwa bahan 
Buletin JSJ, 3 (2), 2021, 83-91

Available online di: http://ejournal-balitbang.kkp.go.id/index.php/JSJ/index

baku udang yang dikirim dari supplier tersebut tergolong masih dalam keadaan segar karena memiliki nilai organoleptik diatas 7 .

Tabel 1. Hasil pengujian organoleptik bahan baku

\begin{tabular}{cccc}
\hline Pengamatan & Interval & Nilai Organoleptik & Standar SNI \\
\hline 1 & $7,65 \leq \mu \leq 7,97$ & 8 & \\
2 & $7,60 \leq \mu \leq 7,99$ & 8 & 7 \\
3 & $7.33 \leq \mu \leq 7,66$ & 7 & \\
4 & $7,50 \leq \mu \leq 7,70$ & 7,5 & \\
5 & $7,45 \leq \mu \leq 7,74$ & 7,5 & \\
\hline & Rata-rata & 7,6 &
\end{tabular}

Bahan baku udang yang telah lulus uji organoleptik kemudian diuji secara mikrobiologi dan kimia. Hasil pengujian mikrobiologi bahan baku udang dapat dilihat pada Tabel 2. Hasil pengujian kimia bahan baku udang dapat dilihat pada Tabel 3 . Hasil pengujian kimia bahan baku udang yang meliputi uji antibiotik kloramfenikol, nitrofuran dan tetrasiklin merupakan data sekunder karena hal tersebut merupakan kebijakan PT.Pulau Mas Khatulistiwa. Hasil pengujian mikrobiologi bahan baku udang vaname menunjukkan bahwa kandungan mikroba yang terdapat dalam bahan baku tidak melebihi batas yang ditetapkan SNI. Hasil pengujian kimia menunjukkan bahwa bahan baku udang vaname tidak mengandung antibiotik kloramfenikol, nitrofuran maupun tetrasiklin. WHO 2001 dalam Kusmarwati et al. 2017 menyatakan bahwa penggunaan antibiotik pada udang hasil budidaya dapat menyebabkan infeksi dan menimbulkan gangguan kesehatan bagi manusia. Oleh karena itu udang budidaya tidak boleh mengandung residu antibiotik. Hasil pengujian mikrobiologi dan kimia menunjukkan bahwa bahan baku udang vaname aman untuk dikonsumsi.

Tabel 2. Hasil pengujian mikrobiologi bahan baku udang

\begin{tabular}{|c|c|c|c|c|c|c|c|c|}
\hline \multirow[b]{2}{*}{ Pengamatan } & \multicolumn{8}{|c|}{ Jenis Pengujian } \\
\hline & $\begin{array}{c}\text { ALT } \\
\text { (kol/g) }\end{array}$ & $\begin{array}{c}\text { Standar } \\
\text { SNI }\end{array}$ & $\begin{array}{c}\text { E.coli } \\
(\mathrm{APM} / \mathrm{g})\end{array}$ & $\begin{array}{c}\text { Standar } \\
\text { SNI }\end{array}$ & $\begin{array}{l}\text { Salmonella } \\
\text { (APM/25 g) }\end{array}$ & $\begin{array}{c}\text { Standar } \\
\text { SNI }\end{array}$ & $\begin{array}{l}\text { V.cholerae } \\
\text { (APM/25 g) }\end{array}$ & $\begin{array}{c}\text { Standar } \\
\text { SNI }\end{array}$ \\
\hline 1 & $\begin{array}{c}2,29 x \\
10^{5}\end{array}$ & & $<3$ & & Negatif & & Negatif & \\
\hline 2 & $\begin{array}{c}2,35 x \\
10^{5}\end{array}$ & & $<3$ & & Negatif & & Negatif & \\
\hline 3 & $\begin{array}{c}2,52 x \\
10^{5}\end{array}$ & $\begin{array}{l}<5 x \\
10^{5}\end{array}$ & $<3$ & $<3$ & Negatif & Negatif & Negatif & Negatif \\
\hline 4 & $\begin{array}{c}2,25 x \\
10^{5}\end{array}$ & & $<3$ & & Negatif & & Negatif & \\
\hline 5 & $2,6 \times 10^{5}$ & & $<3$ & & Negatif & & Negatif & \\
\hline
\end{tabular}


Buletin JSJ, 3 (2), 2021, 83-91

Available online di: http://ejournal-balitbang.kkp.go.id/index.php/JSJ/index

Tabel 3. Hasil pengujian kimia bahan baku udang

\begin{tabular}{ccccccc}
\hline \multirow{2}{*}{ Pengamatan } & \multicolumn{5}{c}{ Jenis Pengujian } \\
\cline { 2 - 6 } & Klorafenikol & $\begin{array}{c}\text { Standar } \\
\text { SNI }\end{array}$ & Nitrofuran & $\begin{array}{c}\text { Standar } \\
\text { SNI }\end{array}$ & Tetrasiklin & $\begin{array}{c}\text { Standar } \\
\text { SNI }\end{array}$ \\
\hline 1 & ND & & ND & & ND & \\
2 & ND & & ND & 0 & ND & \\
3 & ND & $0(\mu \mathrm{g} / \mathrm{kg})$ & ND & $(\mu \mathrm{g} / \mathrm{kg})$ & ND & $<100$ \\
4 & ND & & ND & & ND & \\
5 & ND & & ND $/ \mathrm{kg})$ \\
\end{tabular}

ND : not detected

\section{Pengamatan penerapan rantai dingin}

Penerapan rantai dingin selama proses pengolahan akan mempengaruhi mutu produk yang dihasilkan. Pengamatan rantai dingin yang dilakukan di PT.Pulau Mas Khatulistiwa meliputi pengukuran suhu produk, suhu air dan suhu ruangan proses. Hasil pengukuran suhu udang pada setiap alur proses dapat dilihat pada tabel 4. Hasil pengukuran suhu air yang digunakan selama proses pembuatan produk udang PND dapat dilihat pada Tabel 5. Hasil pengukuran suhu ruangan proses dapat dilihat pada tabel 6.

Tabel 4. Hasil pengukuran suhu udang pada setiap alur proses

\begin{tabular}{clcc}
\hline No & \multicolumn{1}{c}{ Alur Proses } & $\begin{array}{c}\text { Suhu Udang } \\
(-\mathrm{O})\end{array}$ & $\begin{array}{c}\text { SNI } \\
(\mathrm{o} \mathbf{C})\end{array}$ \\
\hline 1 & Penerimaan Bahan Baku & 4,0 & \\
2 & Pencucian 1 & 2,9 & \\
3 & Penimbangan 1 & 2,6 & \\
4 & Pemotongan Kepala, Pengupasan dan & 3,5 & \\
& Pembuangan usus & 3,0 & $<5$ \\
5 & Pencucian 2 & 3,3 & \\
6 & Penimbangan 2 & 3,5 & \\
7 & Sortasi & 2,9 & \\
8 & Soaking & $-26,4$ & \\
\hline 9 & Pembekuan & $-21,4$ & $<-18$ \\
10 & Glazing & $-18,7$ & \\
11 & Pengemasan & $-19,6$ & \\
12 & Penyimpanan & & \\
\hline
\end{tabular}

Tabel 5. Hasil pengukuran suhu air

\begin{tabular}{clcc}
\hline No & Tahapan Proses & $\begin{array}{c}\text { Suhu Air } \\
\left({ }^{\circ} \mathbf{C}\right)\end{array}$ & $\begin{array}{c}\text { Standar SNI } \\
\left({ }^{\circ} \mathrm{C}\right)\end{array}$ \\
\hline 1 & Pencucian 1 & 2,1 & \\
2 & Pencucian 2 & 2,9 & \\
3 & Sortasi & 2,5 & $<5$ \\
4 & Soaking & 1,8 & \\
\hline
\end{tabular}


Buletin JSJ, 3 (2), 2021, 83-91

Available online di: http://ejournal-balitbang.kkp.go.id/index.php/JSJ/index

Tabel 6. Hasil pengukuran suhu ruangan proses

\begin{tabular}{|c|c|c|c|c|}
\hline No & \multicolumn{2}{|c|}{ Tahapan proses } & \multirow{2}{*}{$\begin{array}{c}\text { Suhu } \\
\text { Ruangan (ㅇ) } \\
22,9\end{array}$} & \multirow[t]{2}{*}{$\begin{array}{c}\text { Standar } \\
\text { Perusahaan }\left({ }^{\circ} \mathrm{C}\right) \\
\end{array}$} \\
\hline 1 & Penerimaan Bahan Baku & \multirow{4}{*}{ Pengupasan, } & & \\
\hline 2 & $\begin{array}{l}\text { Pemotongan Kepala, } \\
\text { Pembuangan Usus }\end{array}$ & & 23,0 & \multirow{3}{*}{$22-25$} \\
\hline 3 & Sortasi & & 22,5 & \\
\hline 4 & Soaking & & 22,4 & \\
\hline 5 & Pengemasan & & 18,3 & $18-22$ \\
\hline 6 & Cold storage & & $-22,3$ & $(-20)-(-25)$ \\
\hline
\end{tabular}

Penerapan rantai dingin selama proses pengolahan diperlukan untuk menjaga kualitas produk akhir. Moeljanto 1992 menyatakan bahwa pendinginan ikan merupakan salah satu proses yang umum digunakan untuk menghambat kegiatan mikroorganisme dan proses-proses kimia serta fisis lainnya yang dapat mempengaruhi/menurunkan kesegaran (mutu) ikan. Adawyah (2006) menyatakan bahwa suhu rendah sangat efektif untuk menghambat pertumbuhan bakteri psychrophilic (bakteri yang senang pada suhu rendah dan hidup pada suhu $0^{\circ} \mathrm{C}-30^{\circ} \mathrm{C}$, dengan suhu optimum $15^{\circ} \mathrm{C}$ ). Pengamatan penerapan rantai dingin di PT. Pulau Mas Khatulistiwa meliputi pengamatan suhu udang pada setiap tahapan proses, suhu air serta suhu ruangan selama proses pembuatan produk udang PND. Berdasarkan Tabel 4 dapat dilihat bahwa suhu udang mulai dari penerimaan bahan baku sampai proses soaking memenuhi standar SNI 01-2728.3-2006 yaitu $<5^{\circ} \mathrm{C}$ dan suhu udang saat pembekuan sampai penyimpanan (storaging) memenuhi standar SNI 3457:2014 yaitu < $-18$.

Berdasarkan Tabel 5 dapat dilihat bahwa suhu air yang digunakan untuk proses pencucian udang, sortasi dan soaking sesuai dengan standar SNI. Quality control di PT.Pulau Mas Khatulistiwa melakukan pengecekan suhu air yang digunakan saat proses produksi secara berkala. Hal ini dilakukan sebagai salah satu cara untuk mempertahankan kesegaran udang.

\section{Mutu Udang PND}

Pengujian organoleptik udang PND beku mengacu pada SNI 3457-2014. Hasil pengujian organoleptik udang PND beku dapat dilihat pada Tabel 7. Hasil pengujian mikrobiologi udang PND beku dapat dilihat pada Tabel 8. Berdasarkan Tabel 7 dapat dilihat bahwa nilai organoleptik udang PND beku yaitu 8. Nilai organoleptik yang diperoleh telah memenuhi standar SNI 3457-2014 dengan nilai minimal 7. Spesifikasi udang PND beku tersebut ditunjukkan dengan lapisan es yang rata dan bening, lapisan es cukup tebal pada seluruh permukaan, tidak ada dehidrasi pada permukaan udang, tidak terjadi diskolorisasi pada permukaan produk, serta kenampakan udang masih utuh bercahaya setelah dilakukan proses thawing. Berdasarkan Tabel 8 dapat dilihat bahwa hasil pengujian mikrobiologi produk akhir di PT.Pulau Mas Khatulistiwa memenuhi persyaratan SNI. 
Buletin JSJ, 3 (2), 2021, 83-91

Available online di: http://ejournal-balitbang.kkp.go.id/index.php/JSJ/index

Tabel 7. Hasil pengujian organoleptik udang PND beku

\begin{tabular}{|c|c|c|c|}
\hline No & $\begin{array}{l}\text { Interval Nilai } \\
\text { Organoleptik }\end{array}$ & Nilai & $\begin{array}{c}\text { Standar } \\
\text { SNI }\end{array}$ \\
\hline 1 & $8,05 \leq \mu \leq 8,35$ & 8 & \multirow{6}{*}{7} \\
\hline 2 & $8,0 \leq \mu \leq 8,30$ & 8 & \\
\hline 3 & $8,20 \leq \mu \leq 8,55$ & 8 & \\
\hline 4 & $8,11 \leq \mu \leq 8,40$ & 8 & \\
\hline 5 & $8,19 \leq \mu \leq 8,44$ & 8 & \\
\hline & Rata-rata & 8 & \\
\hline
\end{tabular}

Tabel 8. Hasil pengujian mikrobiologi udang PND beku

\begin{tabular}{ccccccccc}
\hline No & $\begin{array}{c}\text { ALT } \\
(\mathbf{k o l} / \mathbf{g})\end{array}$ & $\begin{array}{c}\text { SNI 01- } \\
\mathbf{2 3 3 2 . 3 -} \\
\mathbf{2 0 0 6}\end{array}$ & $\begin{array}{c}\text { E. coli } \\
(\text { APM/g) }\end{array}$ & $\begin{array}{c}\text { SNI 01- } \\
\mathbf{2 3 3 2 . 1 -} \\
\mathbf{2 0 0 6}\end{array}$ & $\begin{array}{c}\text { Salmonella } \\
(\text { APM/25g) }\end{array}$ & $\begin{array}{c}\text { SNI 01- } \\
\mathbf{2 3 3 2 . 2}- \\
\mathbf{2 0 0 6}\end{array}$ & $\begin{array}{c}\text { Vibrio } \\
\text { Cholerae } \\
(\text { APM/25g) }\end{array}$ & $\begin{array}{c}\text { SNI 01- } \\
\text { 2332.4- } \\
\text { 2006 }\end{array}$ \\
\hline 1 & $3,1 \times 10^{4}$ & & $<3$ & & Negatif & & Negatif & \\
2 & $5,4 \times 10^{4}$ & & $<3$ & & Negatif & & Negatif & \\
3 & $4,5 \times 10^{4}$ & $<5 \times 10^{5}$ & $<3$ & $<3$ & Negatif & Negatif & Negatif & Negatif \\
4 & $2,1 \times 10^{4}$ & & $<3$ & & Negatif & & Negatif & \\
5 & $4,8 \times 10^{4}$ & & $<3$ & & Negatif & & Negatif & \\
\hline
\end{tabular}

\section{Rendemen}

Perhitungan rendemen diperlukan untuk mengetahui presentase produk akhir dari bahan baku yang digunakan pada proses produksi. Nilai rendemen udang PND di PT. Pulau Mas Khatulistiwa dapat dilihat pada Tabel 9. Berdasarkan Tabel 9 dapat dilihat bahwa ratarata rendemen untuk udang PND size 16-20, 21-25, 26-30, 31-40, 41-45 berturut-turut adalah $83 \%, 82,5 \%, 82,5 \%, 82,6 \%$ dan $82,1 \%$. Hal ini telah sesuai dengan standar yang telah ditetapkan oleh perusahaan yaitu $81-83 \%$.

Tabel 9. Nilai rendemen udang PND di PT.Pulau Mas Khatulistiwa

\begin{tabular}{cccc}
\hline No & Size & $\begin{array}{c}\text { Rata-rata } \\
\text { rendemen }\end{array}$ & $\begin{array}{c}\text { Standar } \\
\text { Perusahaan }\end{array}$ \\
\hline 1 & $16-20$ & 83 & \\
2 & $21-25$ & 82,5 & \\
3 & $26-30$ & 82,5 & $81-83 \%$ \\
4 & $31-40$ & 82,6 & \\
5 & $41-45$ & 82,1 & \\
\hline
\end{tabular}

\section{Produktivitas tenaga kerja}

Secara umum produktivitas diartikan sebagai hubungan antara hasil nyata maupun fisik (barang-barang atau jasa) dengan masuknya yang sebenarnya. Produktivitas mengikutsertakan pendayagunaan secara terpadu sumberdaya manusia dan keterampilan, barang modal, teknologi, manajemen, informasi, energi, dan sumber-sumber lain menuju kepada pengembangan dan peningkatan standar hidup untuk seluruh masyarakat. Pada tingkat perusahaan, pengukuran produktivitas terutama digunakan sebagai sarana manajemen untuk menganalisa dan mendorong efesiensi produksi (Sinungan, 2014).

Produktivitas tenaga kerja mempunyai peranan penting dalam pencapaian tujuan perusahaan. Tingkat produktivitas yang tinggi dapat mengefisienkan waktu dalam bekerja sehingga dapat menghasilkan produksi yang sempurna dan menekan biaya produksi. Perhitungan produktifitas dilakukan dengan cara menghitung jumlah produk yang dapat 
Available online di: http://ejournal-balitbang.kkp.go.id/index.php/JSJ/index

dihasilkan setiap orang pada setiap satuan waktu. Hasil perhitungan produktivitas tenaga kerja dapat dilihat pada Tabel 10. Berdasarkan Tabel 10 dapat dilihat bahwa produktivitas tenaga kerja pengolahan udang PND beku di PT. Pulau Mas Khatulistiwa untuk karyawan yang memiliki masa kerja kurang dari 3 bulan yaitu 11,61 kg/jam/orang; lebih dari 3 bulan yaityu 13,32 kg/jam/orang; lebih dari 6 bulan yaitu 15,27 kg/jm/orang; lebih dari 1 tahun yaitu $18,56 \mathrm{~kg} / \mathrm{jam} /$ orang; dan karyawan yang memiliki masa kerja lebih dari 3 tahun yaitu 22,36 $\mathrm{kg} / \mathrm{jam} /$ orang. Produktivitas tenaga kerja pengolahan udang PND beku di PT.Pulau Mas Khatulistiwa semakin meningkat seiring dengan bertambahnya pengalaman bekerja. Semakin lama bekerja, karyawan semakin mahir dan cekatan dalam mengolah bahan baku udang menjadi udang PND. Karyawan pengolah udang yang memiliki masa kerja kurang dari 3 bulan sampai yang memiliki masa kerja lebih dari 3 tahun memiliki produktivitas tenaga kerja yang sesuai dengan standar yang ditetapkan oleh perusahaan.

Tabel 10. Produktivitas tenaga kerja di PT.Pulau Mas Kahtulistiwa

\begin{tabular}{cccc} 
No & Masa Kerja & $\begin{array}{c}\text { Rata-rata } \\
\text { Produktifitas } \\
\text { (kg/jam/orang) }\end{array}$ & $\begin{array}{c}\text { Standar } \\
\text { Perusahaan } \\
\text { (kg/jam/orang) }\end{array}$ \\
\hline 1 & $<3$ bulan & 11,61 & \\
2 & $>3$ bulan & 13,32 & \\
3 & $>6$ bulan & 15,27 & $>10$ \\
4 & $>1$ tahun & 18,56 & \\
5 & $>3$ tahun & 22,36 & \\
\hline
\end{tabular}

\section{KESIMPULAN SARAN}

Proses pengolahan udang kupas mentah beku (peeled and deveined) di PT. Pulau Mas Khatulistiwa telah sesuai dengan standar perusahaan dan juga standar SNI (Standar Nasional Indonesia). Mutu bahan baku, mutu produk akhir, suhu produk, suhu air dan suhu ruangan proses telah sesuai dengan standar SNI. Rendemen produk akhir dan produktivitas tenaga kerja karyawan pengolah udang kupas mentah beku telah sesuai dengan standar yang ditetapkan perusahaan. Hal ini mengindikasikan bahwa udang kupas mentah beku yang diproduksi oleh PT.Pulau Mas Khatulistiwa aman untuk dikonsumsi.

Saran yang dapat diberikan adalah perlu dilakukan penelitian lanjutan tentang pengamatan alur proses pembuatan udang kupas mentah beku serta pengujian secara langsung kandungan antiobiotik pada bahan baku udang vaname.

\section{DAFTAR PUSTAKA}

Adawyah, R. (2006). Pengolahan dan Pengawetan Ikan. Jakarta : Bumi Aksara

[BSN] Badan Standardisasi Nasional. Standar Nasional Indonesia 01-2332.4-2006. Penentuan Vibrio cholerae pada Produk Perikanan. Jakarta (ID): Badan Standardisasi Indonesia.

[BSN] Badan Standardisasi Nasional. Standar Nasional Indonesia 01-2332.2-2006. Penentuan Salmonella spp. pada Produk Perikanan. Jakarta (ID): Badan Standardisasi Indonesia.

[BSN] Badan Standardisasi Nasional. Standar Nasional Indonesia 01-2332.2-2006. Penentuan Coliform dan Escherichia coli pada Produk Perikanan. Jakarta (ID): Badan Standardisasi Indonesia.

[BSN] Badan Standardisasi Nasional. Standar Nasional Indonesia 01-2728.1-2006. Spesifikasi Udang Segar. Jakarta (ID): Badan Standardisasi Indonesia. 
Buletin JSJ, 3 (2), 2021, 83-91

Available online di: http://ejournal-balitbang.kkp.go.id/index.php/JSJ/index

[BSN] Badan Standarisasi Nasional. Standar Nasional Indonesia 3457:2014. Udang Kupas Mentah Beku. Jakarta (ID): Badan Standarisasi Indonesia.

[BSN] Badan Standarisasi Nasional. Standar Nasional Indonesia 01-2332.3-2006. Penentuan Angka Lempeng Total pada Produk Perikanan. Jakarta (ID): Badan Standarisasi Indonesia.

[KKP] Kementerian Kelautan dan Perikanan. (2018). Buku Pintar Kelautan dan Perikanan. Jakarta.

Kusmarwati A, Yennie Y, \& Indriati N. (2017). Resistensi antibiotik pada Vibrio parahaemolyticus dari udang vaname asal pantai utara jawa untuk pasar ekspor. JPB Kelautan dan Perikanan, 12(2), 91-106.

Moeljanto. (1992). Pengawetan dan Pengolahan Hasil Perikanan. Penebar Swadaya. Jakarta.

Sinungan, M. (2014). Produktivitas : Apa dan Bagaimana. Bumi Aksara. Jakarta

Zhu X, Zhang R, Chu F, He Z, \& Li J. (2015). A flexsim-based optimization for the operation process of cold-chain logistics distribution centre. Journal of Applied Research and Technology, 12(2), 270-278. 